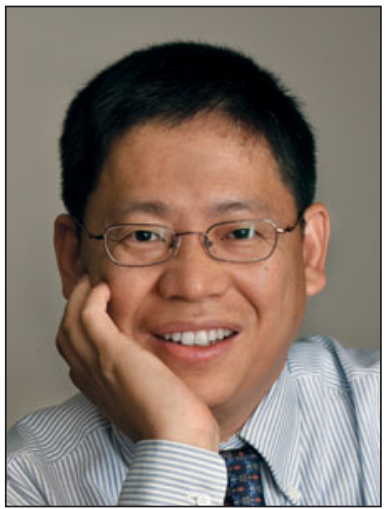

Younan Xia to present Kavli Lecture on nanoscience at 2013 MRS Spring Meeting

Y ounan Xia, the Brock Family Chair and Georgia Research Alliance Eminent Scholar in Nanomedicine at Georgia Institute of Technology, has been selected for the Fred Kavli Distinguished Lectureship in

\section{MRS} Nanoscience. He will give a presentation at the $2013 \mathrm{Ma}$ terials Research Society Spring Meeting on April 1 in San Francisco. The title of his talk is "Colloidal metal nanocrystals - Shape control, symmetry breaking and niche applications."

Xia's research interests include the development of new methodologies for controlling the synthesis of nanostructured materials and exploration of their applications in biomedical research and catalysis. He received his BS degree in chemical physics from the University of Science and Technology of China in 1987, and a PhD degree in physi- cal chemistry from Harvard University in 1996.

Among Xia's numerous awards and honors are the ACS National Award in the Chemistry of Materials (2013), MRS Fellow (2009), NIH Director's Pioneer Award (2006), ACS Leo Hendrik Baekeland Award (2005), Camille Dreyfus Teacher Scholar (2002), David and Lucile Packard Fellow in Science and Engineering (2000), NSF CAREER Award (2000), Alfred P. Sloan Research Fellow (2000), ACS Victor K. LaMer Award (1999), and Camille and Henry Dreyfus New Faculty Award (1997). He has co-authored more than 500 publications in peer-reviewed journals, with an $h$-index of 129. Xia has been named a Top 10 Chemist and Materials Scientist based on the number of citations per paper. He has served as an associate editor of Nano Letters since 2002.

ISIC17 to be held in Japan in May 2013

http://sspns.phys.tohoku.ac.jp/isic17/

T he focus of the 17th International Symposium on Intercalation Compounds (ISIC17), to be held on May 12-16, 2013 in Sendai, Japan, will be on the physics, chemistry, and materials science of intercalated compounds.
The conference, chaired by Katsumi Tanigaki of Tohoku University, includes oral and poster presentations and plenary sessions. It is endorsed by the Materials Research Society. More information can be accessed at the website http://sspns.phys.tohoku.ac.jp/ isic17/ or from Hidekazu Shimotani, Conference Secretary, ISIC17_pr@ sspns.phys.tohoku.ac.jp.

\title{
EUROMAT 2013 to be held in Spain
} http://euromat2013.fems.eu

$\mathbf{T}$ The biennial Federation of European Materials Societies (FEMS) event EUROMAT 2013-European Congress and Exhibition on Advanced Materials and Processes will be held in Seville, Spain, on September 8-13, organized by Sociedad Española de Materiales and Sociedade Portuguesa des Materiais.

The symposia will be presented in seven topical clusters, featuring func- tional materials, structural materials, processing, characterization and modeling, energy and environment, biomaterials and health care, and education, strategy, and technology transfer. The conference includes an equipment exhibit and a day of tutorials.

Plenary lectures will be given by Nobel laureate Yuan T. Lee, president of the International Council of Science; Joanna Aizenberg of Harvard University; Claes-
Göran Granquvist of the University of Uppsala; Paul Midgley of the University of Cambridge; Luigi Nicolais of the University of Naples; and Zhong Lin Wang of Georgia Institute of Technology.

Pre-registration rates are available until May 31, 2013. More information can be accessed at the website http:// euromat2013.fems.eu or from Gonzalo Bilbao, Conference Secretary, Euromat2013@vibocongresos.com. 